http://dx.doi.org/10.12795/PH.1988.v03.i01.09

\title{
LA BUSQUEDA DE UN NUEVO HUMANISMO EN «MOTIVOS DE PROTEO»
}

\author{
Carmen de Mora \\ Universidad de Sevilla
}

A veces la fama de un libro obstaculiza el conocimiento de las restantes producciones de un escritor. El éxito de Ariel eclipsó la importancia de los Motivos de Proteo, el libro más personal e íntimo del pensador uruguayo. Sin embargo, en los últimos años, la crítica tradicional, dividida entre el elogio fácil y el rechazo arbitrario, ha dejado paso a estudios más objetivos y juicios más aquilatados, entre ellos los de Emir Rodríguez Monegal y Carlos Real de Azúa que le han restituido no pocos de sus méritos.

Para valorar la contribución del libro a la evolución del ensayo hispanoamericano es preciso tener en cuenta el contexto ideológico e intelectual del Uruguay de la época y la respuesta de Rodó a los problemas que en ella se plantearon. No obstante, antes de arriesgar alguna conclusión se impone un análisis de la complejidad estructural del libro que cifro en tres aspectos: 1) la situación contextual y discursiva; 2) identificación de los criterios conceptuales; 3) mecanismos discursivos.

\section{La situación contextual y discursiva}

La obra va precedida de unas palabras liminares del autor dirigidas al público lector, donde explica y justifica la naturaleza y arquitectura de la misma concebida como «libro abierto»:

«Y nunca Proteo se publicará de otro modo que de éste; es decir, nunca le daré "arquitectura" concreta, ni término forzoso; siempre podrá seguir desenvolviéndose, "viviendo". La índole del libro (si tal puede llamársele) consiente, en torno de un pensamiento capital, tan vasta ramificación de ideas y motivos, que nada se opone a que haga 
de él lo que quiero que sea: un libro en perpetuo «devenir», un libro abierto sobre una perspectiva indefinida» ${ }^{1}$.

Alfonso Reyes reconoce en esta definición no sólo una manera de bautizar el libro sino una cuestión estética, una completa teoría del libro que tuvo en América sus epígonos, buenos y malos ${ }^{2}$.

La apertura aludida por Rodó se refiere evidentemente a la arquitectura fragmentaria del libro y a la relación del autor con el mismo. El diseño de Motivos era de tal naturaleza que le permitía añadir, a voluntad, nuevos elementos de forma indefinida. Distinto es el concepto de Obra abierta teorizado por U. Eco, que exige la participación activa del lector.

El fragmento introductorio reseñado corresponde a la situación contextual en la que Rodó se dirige a sus lectores y críticos y sirve de pórtico a la situación discursiva. También ésta va acompañada de un epítome, de carácter literario, sobre la figura mitológica que da título al libro y encarna, para el autor, la personalidad humana:

«Siempre inasible, siempre nuevo, recorría la infinitud de las apariencias sin fijar su esencia sutilísima en ninguna. Y por esta plasticidad infinita, siendo divinidad del mar, personificaba uno de los aspectos del mar; era la ola multiforme, huraña, incapaz de concreción ni reposo, la ola que ya se rebela, ya acaricia; que unas veces arrulla, otras atruena; que tiene todas las volubilidades del impulso, todas las vaguedades del color, todas las modulaciones del sonido; que nunca sube ni cae de un modo igual, y que tomando y devolviendo al piélago el líquido que acopia, impone a la igualdad inerte la figura, el movimiento y el cambio» ${ }^{3}$.

Carlos Real de Azúa atribuye la elección del mito a la influencia de Sainte Beuve y, sobre todo, de Emerson, además de identificarlo, por su connotación marina, con el inconsciente. Al margen de posibles influencias, Rodó elige la divinidad marina porque de todas las formas que la Naturaleza ponía a su alcance era la que más se ajustaba a su espíritu: «Abro el pecho y el alma es ambiente marino; siento como si mi sustancia espiritual se reconociese en su centro».

Los textos introductorios sugieren una correlación de fuerzas entre la estructura del libro y la idea central que lo genera. Si la primera consiste en una ramificación de ideas y motivos en torno a un pensamiento capital que puede completarse indefinidamente - a modo de variaciones sobre un tema - , la segunda simboliza la personalidad humana en el mito de Proteo. Proteo o la metamorfosis de lo idéntico. Este principio, clave del pensamiento goethiano

1 J. E. Rodó: Obras Completas, introducción, prólogo y notas de Emir Rodríguez Monegal, Aguilar, Madrid 1967, 2. ${ }^{\text {a }}$ edic., págs. 308-309. En lo sucesivo cito por esta edición.

3 J. E. Rodó: Obras completas, ob. cit., pág. 309. 
aplicado a la ciencia natural, puede extrapolarse al mundo espiritual y, más concretamente, al alma humana. Se ha señalado la influencia del pensamiento evolucionista de Bergson en Rodó, pero Goethe es uno de los orígenes del pensamiento evolucionista en el siglo XIX que llegará hasta Nietzsche. Rodó proponía la renovación continua de la personalidad, es cierto, mas sin abandonar el hilo conductor, sin perder su identidad en los cambios sucesivos, de ahí la conexión con el citado principio goethiano.

\section{Identificación de los criterios conceptuales}

Obra ensayística, Motivos de Proteo juega con la tensión entre los contenidos ideológicos que pretende transmitir y el tono poético adoptado. El discurso literario sirve de canal transmisor a otros códigos extraliterarios pertenecientes al mundo de las ideas, especialmente la filosofía y la psicología. Literatura de ideas denominaba Rodó a este género ${ }^{4}$ por no utilizar expresiones menos adecuadas, como literatura docente o trascendental.

Una misma intención anima la prosa de Ariel y de Motivos: servir de guía espiritual a la juventud americana, y punto de partida del proyecto, más amplio, de darle una base ideológica a las jóvenes naciones americanas, poco habituadas a pensar por sí mismas. Contra lo que pudiera pensarse, la polaridad ideológica de Rodó no afecta el lado artístico de la obra, pues para él no existe obra realmente literaria sin estilo, de ahí la preocupación por los aspectos artísticos y formales que se advierte en sus ensayos. Si en lo expresivo denota la filiación modernista, en el pensamiento asume «un ideal constructivo de trascendencia social» proyectado hacia el futuro de América. En el borrador de una carta a Andrés González Blanco (19 de junio de 1909) escribe:

«Creo que la tendencia que ganará terreno cada día en las letras contemporáneas es la que les mueve a interesarse en ideas y propósitos sociales, de alta y noble educación humana, y creo también que el sentido de esa tendencia puede y será optimista, afirmativo, viril; de franca reconstrucción idealista, en armonía con direcciones filosóficas que cada vez se definen más clara y enérgicamente en todas partes donde se piensa con originalidad».

Refiriéndose a la naturaleza orgánica de Motivos la asociaba Rodó con las obras de los «ensayistas» ingleses por «la mezcla de moral práctica y filosofía de la vida con el ameno divagar, las expansiones de la imaginación y las galas del estilo; pero todo ello animado y entendido por un soplo 'meridional'... y todo unificado, además, por un pensamiento fundamental que dará unidad orgánica a la obra...» ${ }^{5}$. 1.383.

4 Carta a Unamuno (25 de febrero de 1901), en J. E. Rodó: Obras Completas, ob. cit., pág.

5 Carta a Juan Francisco Piquet (6 de marzo de 1904) en J. E. Rodó: Obras completas, op. cit, pág. 1.344 . 
La idea de obra orgánica es un concepto que Schlegel aplicó al Guillermo Meister de Goethe para marcar la interdependencia entre los distintos elementos de la novela por ser etapas metamórficas y manifestaciones sucesivas del mismo principio. Caracterizaba así una obra de arte orgánica que obedecía a las leyes de la naturaleza, repitiendo en su estructura la organización del universo como un todo animado. Variedad y multiplicidad unificadas por un pensamiento conductor son premisas necesarias para aproximarnos a Motivos. El tema central es la transformación de la personalidad hacia su propio perfeccionamiento, idea que adopta múltiples modulaciones en su desarrollo conceptual.

Para mayor claridad expositiva distingo cinco grandes apartados en la estructura del libro:

1. La transformación de la personalidad: Reformarse es vivir (I-XI).

2. La casa de Psiquis. La introspección en lo inconsciente (XII-XXXIX).

3. La vocación y la aptitud (XL-LXXIX) (CIV-CX).

4. La convicción y la fe (CXI-CXLVII).

5. La voluntad: la vida como arte supremo (CXLVIII-CLVIII).

\section{La transformación de la personalidad}

«Reformarse es vivir» - afirma Rodó. «O rinnovarse o morire» - dijo d'Annunzio. El punto de partida de Rodó es que el hombre, lo quiera o no, se transforma mientras vive por acción del tiempo que es el «summo innovador». Idea esta de la fuerza creadora del tiempo bastante usual entre los pensadores románticos, formulada entre otros por Herdenberg. Sometido a sucesivas transformaciones psíquicas, el hombre adopta múltiples personalidades, de ahí su carácter proteico. Tales transformaciones tendrían lugar por acumulación de acciones insensibles, pues no hay impresión por leve que sea que no deje una huella en nuestra personalidad. Es lo que el autor denomina, utilizando un préstamo científico, causas actuales.

Lo que salva al hombre de una transformación incontrolada y dispersa es el concurso de la inteligencia vigilante y la voluntad activa, el sometimiento de los actos a un raciocinio consciente de la transformación sin tregua del hombre y de las cosas. Así como el mundo físico, también el espiritual tiene sus propias leyes. En Motivos de Proteo la más importante es la ley de la persistencia indefinida de la educación: «mientras vivimos, nada hay en nosotros que no sufra retoque y complemento. Todo es revelación, todo es enseñanza» ${ }^{6}$.

El esquema de una vida bien ordenada corresponde a una línea curva que cambia constantemente de dirección, pero cada dirección que toma está indicada de antemano por lo que le precede. Curiosa coincidencia con la estructura del libro, donde cada epígrafe trata una nueva cuestión y a su vez sirve de punto de partida a la que tratará en el siguiente.

Postula Rodó una filosofía viril que estimule al hombre a renovar continuamente su energía vital y convierta el fracaso en ejercitación para una nueva victoria, «estímulo y objeto para un nuevo sentido de la acción». 
Tras dejar paso a otros temas retorna a la idea primitiva a partir del capítulo LXXX. Definida como natural virtualidad del alma la tendencia a modificarse y renovarse, es preciso canalizarla y organizarla dentro de un orden con el consenso de la razón y la voluntad.

\section{La casa de Psiquis. La introspección de lo inconsciente}

Este segundo motivo enlaza directamente con el anterior. Es al mismo tiempo su antítesis y complemento. Se refiere a las aptitudes latentes - reservas las llama - que ayudan al hombre a superar el fracaso de una vocación a la que había consagrado todas sus energías. Frente a la ley de la persistencia indefinida de la educación, donde participan activa, conscientemente, la inteligencia y la voluntad, las reservas constituyen la parte virtual de nuestra personalidad que sólo se manifiesta en determinadas circunstancias, cuando se busca un nuevo impulso de acción para superar un fracaso. Esa búsqueda debe orientarse hacia la introspección, ahondando en la conciencia de sí mismo no en actitud contemplativa sino a través de la acción. Ya profetizó Herder: «¿Buscas la gran ley que mueve los mundos? ¡Oh ser mortal! mira en tu fondo. Allí encontrarás la regla más elevada que no sólo mueve el mundo sino también se mueve a sí misma». Herder proponía el autoconocimiento para conocer la vida. Rodó, a partir del autoconocimiento, invitaba al individuo a transformarse para transformar la vida.

A medida que profundiza en la personalidad y su disponibilidad transformadora se revela la complejidad personal en un perpetuo llegar a ser. Dos factores estimulan el cambio; uno, de orden externo, es la variedad y la heterogeneidad de las cosas y los acontecimientos; otra, de orden interno, corresponde a los pozos comunicantes, al mandato del instinto, punto donde convergen los influjos de antiguas generaciones, la herencia de nuestros antepasados. Cualquiera de estas dos fuerzas o ambas a la vez pueden provocar una de las ráfagas que descubren perfiles inéditos de nuestra personalidad.

El dominio del inconsciente explica la aparición de seres extraordinarios y superiores, ya sea en el orden intelectual o en lo moral, por el fenómeno de la variación espontánea, expresión aplicada por el evolucionismo a las especies naturales que Rodó trasplanta al campo de la personalidad humana:

«Lo que nos parece instantáneo, improviso, y como comunicado por una potestad superior, en las bruscas transformaciones de nuestra vida moral, no es, la mayor parte de las veces, sino el resultado visible, la tardía madurez, de una acción larga y lentamente desenvuelta en el abismo interior, teniendo por arranque una moción levísima» ${ }^{7}$.

Un fenómeno similar ocurre en la vida consciente con los actos nimios: muchos de los grandes inventos y descubrimientos del hombre han tenido como punto de partida un acto u observación aparentemente insignificante: la manzana de Newton, la lámpara de Galileo o la marmita de vapor de Worcester.

Ibid., p. 339. 


\section{La vocación y la aptitud}

La más poderosa energía que libera el inconsciente para el perfeccionamiento de la personalidad es la vocación: «la vocación prevalece sobre los más altos y categóricos motivos de determinación voluntaria».

De la mano de un idealismo pragmático analiza, primero, la vocación en el mundo de la infancia a tenor de su afán educacionista. Le interesa no el fruto maduro, presto a caer del árbol, sino el grano apto para germinar. Analiza el presente mirando con optimismo hacia el futuro.

La manifestación espontánea, por así decirlo, de la vocación, no excluye una vocación dirigida por la voluntad. Este sería el sentimiento amoroso: «por el estímulo a ennoblecerse y mejorarse que el amor inspira suyo preferentemente es el poder iniciador en las mayores vocaciones de la energía y de la inteligencia», porque el sentimiento de belleza que va asociado al amor puede cristalizarse en representaciones artísticas. El amor, en efecto, sería el estímulo más general y remoto, pero aún caben otros más directos y concretos como el hecho provocador, que revela una aptitud determinada en un momento preciso, la percepción directa o por referencia de aquello para lo que se demuestra aptitud o la sugestión, especialmente a través de la lectura.

En la gran unidad temática de la vocación despliega el autor tal cantidad de variantes y ejemplos que, si no agotan el tema, exasperan al lector abrumado por un copioso catálogo de artistas, escritores y hombres de acción.

A fuerza de proponer modelos para la sociedad hispanoamericana, meta última de Rodó que justifica el didactismo edificante de los Motivos, incurre en la actitud que tanto había criticado a los modernistas: el distanciamiento de la realidad propia $^{8}$. El acendrado individualismo del escritor hace crisis en la preocupación, más que sincera, por el futuro de América. El mismo reconoció, sin poder evitarlo, el anacronismo de esta postura que contradecía el avance del socialismo como modelo de convivencia y el progresivo auge de las masas.

\section{La convicción y la fe}

Tanto la vocación como la fe están subordinadas a la renovación de la personalidad. Rodó se detiene en ellas porque resultan dos potentes motores de la voluntad hacia la perfección del individuo. Defiende la fe que resurge de las porfías de la duda frente a la fe petrificada, la sinceridad de una convicción frente a la práctica de una fe mentida. Para Rodó no «hay término final en el descubrimiento de lo verdadero, no hay revelación una, cerrada y absoluta; sino cadena de revelaciones...». En el hallazgo de la fe es necesaria la intervención del pensamiento y del sentimiento, aunque ninguno sea suficiente para disipar definitamente la duda.

8 No obstante, existen alusiones indirectas en los capítulos LXXIII y LXXIV, donde se ocupa de la lucha entre la aptitud individual y la resistencia del medio. Carlos Real de Azúa cita los capítulos LXIV y LXXVII, donde Rodó se refiere a las condiciones de la creación intelectual en América. 


\section{La voluntad}

Se entiende que en el pensamiento del escritor uruguayo la voluntad adquiere un poder preeminente: ella es el motor que transforma al hombre y lo conduce a la propia superación. Al final confiesa que su mensaje no sólo es válido para el individuo, sino para la colectividad entera, para el destino de un pueblo. Las mismas premisas aplicadas al análisis de la personalidad individual le sirven, pues, para analizar el genio de un pueblo, el espíritu de una raza.

Considerados así los temas, se impone una reflexión sobre el pensamiento que los anima. Más que filósofo Rodó es un pensador que escoge y selecciona de los sistemas filosóficos de su tiempo una serie de postulados que desarrolla de forma ensayística. El mismo se autodefine en «Rumbos Nuevos» (Mirador de Próspero) como neoidealista. Defiende no el idealismo de espiritualistas y románticos de 1830, sino otro que restituyendo la soberanía a las ideas está tamizado por la herencia positivista, de la que Rodó admiraba su potente sentido de relatividad en la misma medida que despreciaba su empirismo utilitarista. De entre las numerosísimas fuentes manejadas por Rodó para la elaboración de Motivos, la crítica ha espigado unos cuantos nombres: Montaigne, Guyau, Spencer, Renan y Bergson. Recientemente, Udo Rukser, en su estudio titulado Goethe en el mundo hispánico presenta al autor de Motivos como goethiano eminente. Son, en efecto, frecuentes las alusiones al escritor alemán a lo largo de la obra.

Al hablar de la vocación y exponer el caso en que dos vocaciones atraen con idéntica fuerza cita una anécdota muy conocida del escritor alemán donde la incertidumbre se resuelve mediante un compromiso con el azar ${ }^{9}$. Más adelante, alude a la amistad entre Schiller y Goethe como modelo de espíritus antagónicos y complementarios (O. c., pág. 385).

De todas las facetas creadoras de Goethe, le fascinó la de su propia personalidad y la lección de humanismo que fue su vida. No sería extraño que hubiera pensado en él al escribir los Motivos:

«El más alto, perfecto y típico ejemplar de vida progresiva, gobernada por un principio de constante renovación y de aprendizaje infatigable, que nos ofrezca en lo moderno la historia natural de los espíritus, es, sin duda, el de Goethe. Ninguna alma más cambiante que aquélla, vasta como el mar y como él libérrima e incoercible; ninguna más rica en formas múltiples...» (O. c., pág. 406).

«Sísifo de su propia persona» le llama en honor a la voluntad de renovarse perpetuamente cada día.

\section{Mecanismos discursivos}

Motivos de Proteo cumple los requisitos del ensayo en cuanto pensamiento que discurre libremente sobre una motivación temática. Pero, siguiendo el pensamiento de Rodó, la idea no basta para transformar la personalidad y no

9 J. E. Rodó: Obras Completas, ob. cit., pág. 376. En la versión de Rodó, Goethe arroja un puñal al río para ver si se sumergía o flotaba. Carlos Real de Azúa se apoya en esta anécdota para 
arraiga si no la arrastra la sensibilidad - como no basta introducir el guijarro en el tronco para vincularlo a la vida del árbol-; así, el libro es instrumento de reforma interior «no principalmente por la fuerza propia de la idea, sino por la virtud que la idea, pintada y animada, adquiere para tocar los resortes con que se despierta la emoción y se provoca el movimiento...» ${ }^{10}$. Para que exista el libro del artista es preciso «la vida y la pasión de una idea encarnada para revelársenos».

En su propósito de dualizar la fuerza de las ideas con la sensibilidad y plasticidad de las mismas recurre a dos métodos o sistemas expositivos: el método arborescente y el sistema parabólico.

El método arborescente consiste en seleccionar y eliminar a partir de una idea que se dilata en múltiples ramificaciones. El propone una tesis, la explica y, a continuación, contrapone los casos que se desvían de la misma sólo para potenciar al máximo la idea original. Por ejemplo, en el tema de la renovación de la personalidad analiza las siguientes desviaciones:

- facilidad para el cambio por deficiencia de personalidad

- dilettantismo

- renovación falaz y artificiosa.

Este marco se completa con los estímulos que contribuyen al desarrollo de aquélla: los viajes y la soledad, motivos que sirven de punto de partida a nuevos desarrollos temáticos.

Huelga insistir en la analogía de este método con el utilizado en el tratamiento de las especies naturales, pues la teoría de la evolución creadora fuente inspiradora de Rodó- contemplaba el mundo físico y el espiritual. Además, las alusiones continuas al mundo de la naturaleza para explicar fenómenos psíquicos en Motivos testifican este supuesto.

El sistema parabólico corresponde a la técnica de ilustrar las ideas mediante narraciones intercaladas que él mismo denominó cuentos simbólicos o parábolas. Algunas de tanta exquisitez y belleza formal que fueron recopiladas como libro independiente.

Extraño que para muchos lectores esas historias, anécdotas y parábolas resulten un cuerpo extraño y superfluo, no una necesidad interior de su estilo.

Muchas de las fuentes están tomadas directa o indirectamente de la Antigüedad. Recordemos que existía toda una corriente en el siglo XIX - cuyos orígenes pertenecen a una escuela inaugurada en Alemania por Georg Friedrich Creuzer - que encontraba en los mitos «representaciones crípticas de profundas verdades filosóficas» ${ }^{11}$. Difundidas estas ideas en Francia, encontraron amplio eco entre los parnasianos, especialmente Leconte de Lisle, para

mostrar la flexibilidad con que Rodó manejaba las fuentes, pues en las Memorias de Goethe se aludía a un cortaplumas, no a un puñal. (Cfr. C. Real de Azúa, prólogo a Motivos de Proteo, Ayacucho, Caracas 1976, pág. LXXIII.

10 J. E. Rodó, «Proteo», en Obras completas, ob. cit., pág. 924.

11 Cfr. G. Highet: La tradición clásica II, F.C.E., México 1954, pág. 334. 
quienes las leyendas griegas antes de ser objetos decorativos revelaban en su belleza profundas verdades. Visto de otro modo, el refugio en los modelos clásicos no dejaba de ser un rechazo del utilitarismo positivista y de la ausencia de auténticos valores. Por último, era frecuente que los escritores del siglo XIX recurrieran a las historias, personajes y leyendas de la Antigüedad para expresar a través de ellos con más claridad e intensidad emociones o ideas universales por condensar una experiencia o una norma de vida.

La narración parabólica tiene, además, en Rodó una indudable filiación bíblica. «Todo se trata por parábolas» (San Marcos, IV, II)-- reza en el epígrafe que encabeza el libro ${ }^{12}$. Con la diferencia de que en Rodó tiene un sentido aclaratorio más que críptico o cifrado, y que dicha finalidad práctica se complementa en la prosa del montevideano con una búsqueda estética. Alberto Zum Felde los asocia con los «poemas en prosa» y los «pequeños poemas en prosa» definitivamente fijados por Baudelaire pero con raíces en el s. XVIII. Juan Montalvo, José Martí, Leopoldo Lugones, Horacio Quiroga, Amado Nervo y Rubén Darío explotaron al máximo las posibilidades estéticas de la prosa siguiendo la tendencia francesa.

Es difícil e innecesario clasificar las narraciones insertas por Rodó para apoyar e ilustrar las ideas defendidas teóricamente. Sin embargo, pueden distinguirse dos grandes grupos: las que se inspiran en la Antigüedad clásica y las que toman como referente modelos literarios y plásticos, ya sean las obras o los personajes y aun los propios artistas.

1) Entre las primeras está «Un friso del Partenón», ambientada en Atenas y destinada a demostrar, en el reconocimiento de los atenienses a la belleza de sus ancianos, que cada edad tiene su propia belleza. «La respuesta de Leuconoe» reproduce a través de un sueño la respuesta que la joven dio al emperador Trajano invitándole con la palabra «espacio» a extender el imperio hacia tierras desconocidas. Como Leuconoe, Rodó invitaba al lector a conquistar el espacio del alma: «Allí queda infinita extensión por conquistar, mientras dura la vida: extensión siempre capaz de ser conquistada» (O. c., pág. 325).

En la misma línea está «La inscripción del Faro de Alejandría» que su autor, Sóstrato, grabó, por debajo de la que Tolomeo le hizo esculpir con su nombre, para que con el tiempo prevaleciera la verdad, y fuera su nombre y no el del rey el que leyesen las generaciones sobre el mármol eterno. La anécdota es un pretexto para incitarnos a penetrar en nuestra alma liberándola de toda vanidad y adherencia para reconocernos a nosotros mismos.

La trasposición del mundo físico y natural al mundo espiritual y anímico es uno de los mecanismos metafóricos habituales en Rodó, herencia del romanticismo alemán que se propuso reencontrar la perdida unidad original entre materia (naturaleza) y espíritu. A veces, la trasposición ocurre entre el mundo animal y el humano. Tal es el ejemplo de «Los tres cuervos del descubrimiento de Islandia», historia sacada de las crónicas de aquel país. Contiene tres ejem-

12 En Alemania el relato parabólico fue practicado fundamentalmente por Lessing y Goethe. 
plos de las tres actitudes y reacciones que Rodó quiere poner de manifiesto: la del que duda y permanece inmóvil, la del que regresa al punto de partida por temor a lo desconocido y la del que se aventura, se arriesga y descubre nuevos horizontes.

Una de las leyendas más hermosas y poéticas de este grupo: «Ayax». Presenta a la hermosa Urania buscando en vano entre los jacintos del campo romano las letras que completan la A y la Y del nombre de Ayax. Símbolo de los destinos incompletos y las vidas tempranamente segadas. «Hylas», el efebo que acompañaba a Hércules en la expedición de los Argonautas y quedó perdido para siempre bajo las aguas, arrebatado por las ninfas, cautivo de amor, personifica el ideal eternamente perseguido y, por lo tanto, «supremo objeto para los movimientos de nuestra voluntad».

«La despedida de Gorgias» no sólo es una hermosa parábola destinada a combatir el dogmatismo y la creencia en una sola verdad absoluta, sino un autorretrato de Rodó, pues en las palabras del filósofo griego reconocemos el mensaje del escritor uruguayo a la juventud americana:

«Mi filosofía ha sido madre para vuestra conciencia, madre para vuestra razón. Ella no cierra el círculo de vuestro pensamiento. La verdad que os haya dado con ella no os cuesta esfuerzo, comparación, elección; sometimiento libre y responsable del juicio, como os costará la que por vosotros mismos adquirais, desde el punto en que comenceis realmente a vivir» (O. c., pág. 464).

«Los amigos de Pirrón» simboliza, en cambio, el extremo opuesto: el fanatismo llevado hasta sus últimas consecuencias. «Lucrecia y el mago», situada en Egipto, en la época de decadencia del Imperio Romano, deja entrever las reconditeces del alma humana y lo imprevisible de sus derroteros: «Artemio: nunca estimules la seguridad en el justo; la desconfianza en el caído: todos tienen huéspedes que no se le parecen, en lo oculto del alma» (O. c., pág. 477). La falsa fuerza y la falsa originalidad hallan expresión en la historia de Peregrino, filósofo de Bario satirizado por Luciano, quien sacrificó su vida «a la vana codicia de la fama».

La leyenda más reconocida por la crítica, tanto por la belleza formal como por la adecuación con la tesis que la sustenta es la de «Los seis peregrinos». Es la historia del evangelista Endimión y seis peregrinos discípulos suyos que se fueron desviando del camino trazado, excepto Agenor, y sólo dos de ellos se encontraron de nuevo con el maestro al concluir la aventura. Reconoce Rodó la necesidad de una idea rectora que presida nuestra existencia, pero admite dos actitudes encarnadas en dos peregrinos de la leyenda. Agenor, el entusiasta inflexible, alma monocorde y austera, e Idomeneo, cuyo entusiasmo asume las múltiples formas de la vida, y consiente, generoso con su riqueza de amar, otros objetos de atención y deseo que el que preferentemente se propone.

En la mayoría de las historias comentadas la ejemplaridad es positiva. Sólo en dos casos los modelos clásicos son negativos: «Los amigos de Pirrón» y «La pasión de Peregrino». 
2) Los modelos literarios y plásticos. Abunda en este grupo el «exemplum», en sentido aristotélico: «historia que se inserta a manera de testimonio», con preferencia por ciertos personajes literarios o artistas que protagonizaron alguna historia o anécdota edificante. El recurso estaba en Montaigne y, más próximo a Rodó, en Ribot, uno de los grandes psicólogos de la época que - como apunta Real de Azúa - era la base de su cultura psicológica.

De Don Quijote admira la capacidad de reacción y de extraer renovadas fuerzas de cada fracaso. Por eso recuerda aquel episodio en que vencido por el caballero de la Verde Luna, se ve obligado a abandonar la vida de aventuras y superando la tristeza que le produce la nueva situación busca un ideal en la quietud de la vida pastoril. Este episodio completa el desarrollado en la narración parabólica del niño y la copa. En cambio, el Peer Gynt de Ibsen desaprovecha las energías del alma por ignorar la vía de observación interior; había sustituido erróneamente la divisa de «ser él mismo» por la de «bastarse a sí mismo», y al final de su vida reconoce que ésta no había sido sino un largo fracaso.

Para denunciar los obstáculos que se interponen en la libertad creadora del artista rescata la anécdota del pintor Giordano a quien su padre apremiaba, para que pintara de prisa, con la expresión «Luca, fa presto!». Función desmitificadora sobre el origen de las grandes ideas alcanza la anécdota de Rousseau a propósito de su invectiva contra la civilización.

Por último, el empleo sistemático de metáforas, símiles y comparaciones que interceptan el corpus doctrinal instalan en la densidad de las ideas un respiro de transparencia poética, de sueño y leyenda.

Cuando Rodó escribe Motivos de Proteo se ha sedimentado la urgencia americanista que le apremiaba en Ariel. Han transcurrido algunos años desde el desastre de Cuba que tanto afectó su conciencia. Desesperado por la situación caótica que generó en Uruguay la guerra civil de 1904 decide elevarse sobre las circunstancias concretas y ocuparse no de los problemas coyunturales de la sociedad americana, sino de los problemas raigales del hombre. Como la mayoría de los grandes pensadores hispanoamericanos convirtió la educación en la idea hiperbólica de su doctrina:

«... para los que tenemos aficiones intelectuales y tendencias a una vida de pensamiento y de cultura, resultan, más que incómodas, desesperantes las condiciones de este ambiente, donde apenas hay cabida sino para la política impulsiva y anárquica, que concluye por arrebatar en un vértigo a los ánimos más serenos y prevenidos. Yo no aspiro a la «torre de marfil»: me place la literatura, que, a su modo, es milicia, pero cuando se trata de luchar por ideas grandes, de educar, de redimir» (carta a Unamuno, 20 marzo de 1904).

Espíritu apolíneo, quiso huir del caos refugiándose en un ideal de serenidad clásica, y desde tan elevada atalaya ejerció su magisterio imparcial sobre la juventud americana. Cuando a partir del 900 empieza a cundir en América la preocupa- 
ción por las peculiaridades regionales, Rodó apunta hacia una meta universal. Nada, a no ser la necesidad que tenían las jóvenes naciones americanas de ser educadas, identificaría al destinatario real de su mensaje.

Como ensayo filosófico Motivos se aparta del pensamiento americanista que trata de ofrecer soluciones concretas a los problemas del país - caso, por ejemplo, de Mariátegui- y se acoge a las ideas del naturalismo evolucionista, vigente en la filosofía de la época, para proponernos una antropofanía. El hecho de que todos sus ejemplos estén basados en la Antigüedad y en artistas europeos abisma aún más la conexión con la realidad propia. Esta se encuentra, por cierto, en la génesis de Motivos, en el hastío del escritor que huye de la mediocridad del ambiente montevideano y se refugia en la culta Europa, pero la meta es el individuo. Coincido, por esta razón, con Emir Rodríguez Monegal cuando afirma: «lo que hoy queda del libro es el enorme valor de autobiografía espiritual, de comunicación íntima con el espíritu de Rodó». Un espíritu que apostó por la fe en el hombre, en el poder de renovarse y trascenderse incensantemente por el ejercicio de la voluntad o vocación, cuando el hombre, próximo ya al cataclismo de la guerra, se despojaba de todas las certezas.

Motivos es una vertiente del pensamiento proteico de Rodó, inapresable en una sola fórmula. Afirmar la vocación universalista del pensador en este libro no significa negar la preocupación por los problemas de América tratados en otros escritos suyos. Para comprenderle cabalmente tenemos que conocer las infinitas orquestaciones de sus obras.

Desde el punto de vista literario, Motivos de Proteo es una lección de estilo, un cuerpo verbal que transmuta las ideas en metáforas vivas, en claridad reconocible, entregándose con voluptuosidad al mito inicial que lo conforma. 